\title{
How can Amazonian biodiversity contribute to the strengthening of the bioeconomy?
}

\author{
Keywords: biodiversity, nature, bioeconomy, microorganisms, \\ fungi
}

\section{Opinion}

The Amazonian biodiversity is acknowledged to be splendid. But how far the biodiversity of the Amazon forest may contribute to stand upright by itself, in a world with such disparate ambitions to preserve the environment and on the other hand the economic interests eager for finite resources from this same nature? Among extremists adept at preserving nature without touching it, and those favored by deforestation to the detriment of the "development" of the region to bring more wealth to the Amazon people, this topic is considered as a priority on sustainable development debate.

Several research and teaching institutions located in the Amazon (and beyond) seek increasingly realistic and viable alternatives

for sustainable development through Research, Development and Innovation. Biotechnology applied to the economy, known as bioeconomy, employs the applied biotechnology to reduce production costs, replacing synthetic products for biodegradable and renewable products for the creation of products in agriculture and industry. The Amazon Biotechnology Center (Centro de Biotecnologia da Amazônia - CBA) was created with the purpose of employing the enormous biodiversity existing in the Amazon region for the development of processes and products of biotechnological interest in a sustainable way. It also has the function of providing services in order to increase the quality of products, especially those in the Amazon region itself, and also engage in consulting and technological innovation activities in close relationship with companies. Additionally to plants and animals, microorganisms are a virtually inexhaustible source of products of biotechnological importance. Products derived from the action of microorganisms (fungi and bacteria) such as the production of ethanol, food, organic acids, pharmaceuticals and enzymes generate billions of dollars annually in Brazil.

On the other hand, the Amazon region has 30 times less doctors than the average for the rest of Brazil, according to statistics from the National Research Council, despite having more than $20 \%$ of living beings on Earth. In this process of searching for higher professional qualification, the professionalization of scholarship researchers linked to the institutes of science and technology of the region is fundamental, since it will be increasingly aligned the research expectation with the commitment of the researcher. In fact, there is a "Brazilian limitation" in the way of research and development and innovation are treated by governments because while research continues to be treated as amateurs being held by students and/or trained doctors, which has no prospect of continuing their work, there will be no commitment or even dedication to the public cause. Since approximately $90 \%$ of the resources destined to the payment of scholarships in Brazil come from public sector programs. But regardless of governments and priority programs, researchers continue to search for innovative solutions and performing their work in the best way that the scenario can allow.

Despite the scarcity of resources for research, we search for
Volume 6 Issue 3 - 2018

\author{
Augusto Bücker,' Nádia Cristina Falcão \\ Bücker $^{2}$ \\ 'Department of Bioprocess Engineering, Fundação Centro de \\ Análise, Pesquisa e Inovação Tecnológica - FUCAPI, Brazil \\ ${ }^{2}$ Department of Pharmacology, Amazon Biotechnology Center \\ (Centro de Biotecnologia da Amazônia - CBA), Brazil
}

Correspondence: Augusto Bücker, Department of Bioprocess Engineering, Fundação Centro de Análise, Pesquisa e Inovação Tecnológica - FUCAPI, Brazil,Av. Gov. Danilo de Mattos Areosa, 38I - Distrito Industrial - CEP: 69075-35I,Tel +55 922127 . 3034/2 I27-3257, Email abucker@gmail.com

Received: April 18, 2018 | Published: May 21, 2018

solutions for economic and environmental drawback, and the theme of bioeconomics is for research as the main interlocutor between protecting the environment and the concerns of seeing the forest standing without (outwardly) generate profit or monetary wealth. But how can Amazonian biodiversity contribute to the strengthening of the bioeconomy?

A proposal would be to structure a network of technological projects involved in the microbiology field, to bring greater interaction between the laboratories of the region and get related and sequential results between similar lines of research. This will require more scientific technological debates among researchers in the area, as well as the organization of a series of seminars and promotion of specific meetings with guidelines aimed at greater scientific production at national and international level. With a structure in network science labs performing complementary research, can imagine a large phylogenetic tree with different species having studied their metabolisms and associate with each microorganism studied a related product or scientific advance produced. How can Amazonian microbiology contribute to the development of the bioeconomy? Often, a biotechnological progress is due to the discovery and use of products and processes extracted from the biodiversity. Thus, the association between biotechnology and biodiversity is evidenced by bioprospecting of megaprojects in regions that present major nature conservation to reproduce products of industrial application. Highlighting the importance of biotechnology in the economic spectrum and correlating the conservation of biodiversity.

In the biotechnology field, some sectors are the main contributors to the advances observed in bio-businesses, such as food and beverage industries (fermented regional fruit drinks, energy concentrates and nutraceuticals), bio-cosmetics (organic products, vegan and natural origin for hygiene, perfumery and cleaning) and the phytomedicine industry (pharmaceuticals, derived directly or indirectly from plants or microorganisms). The growing demand for natural products developed primarily by riverside communities on a sustainable basis has favored a very strong market trend of new business in the Brazilian Amazon. As part of this trend, advances in biotechnology 
research have demonstrated a key role in expanding this potential, thereby boosting the productive chains of bio-industries in the region.

It is not the purpose of this article exhaust the discussion about biobusiness but help structure a broader concept on biobusiness and also to understand the way innovation is dynamized in the segments of biotechnology and the contribution of microbial biodiversity in the Amazon.

\section{Acknowledgements}

The authors are grateful for the collaborative review of the researchers Dr Alexander Voelkner and Dr. Nivea Maria Falcão Voelkner.

\section{Conflict of interest}

The author declares no conflict of interest. 